\title{
A nova organização do trabalho na universidade pública: consequências coletivas da precarização na saúde dos docentes
}

\author{
The new organization of labor at public universities: \\ collective consequences of job instability on the health of teachers
}

\author{
Katia Reis Souza ${ }^{1}$ \\ André Luis Oliveira Mendonça ${ }^{2}$ \\ Andrea Maria Santos Rodrigues ${ }^{1}$ \\ Eliana Guimarães Felix ${ }^{1}$ \\ Liliane Reis Teixeira ${ }^{1}$ \\ Maria Blandina Marques Santos \\ Marisa Moura ${ }^{1}$
}

${ }^{1}$ Centro de Estudos da Saúde do Trabalhador e Ecologia Humana, Escola Nacional de Saúde Pública, Fiocruz. R. Leopoldo Bulhões 1480, Manguinhos. 21041-210 Rio de Janeiro RJ Brasil.

katreis@ensp.fiocruz.br ${ }^{2}$ Instituto de Medicina Social, Universidade do Estado do Rio de Janeiro. Rio de Janeiro RJ Brasil.
Abstract The main objective of this article is to analyze the new organization of labor of university teachers, seeking to investigate the potential relationship with the health status of these workers. It is based on the assumption that job instability in public universities has had repercussions on the health of higher education teachers. A qualitative exploratory study was conducted by means of bibliographic research in indexed databases. As a method of analysis, thematic analysis was used, focusing on four empirical categories, namely: job instability in the teaching profession; intensification of labor; aspects of the organization of teaching work in universities; and data on the health of university teachers. It was revealed in the literature that the use of strong organizational pressures prevails in the university scenario and consequently the intensification of labor is prevalent, with emphasis on the issue of increasing the demand for academic productivity. It was also observed that the topic of excess workload of teachers is recurrent and the concept of availability of less leisure time prevails. In addition, the need for organized collective resistance was confirmed in order to modify the job instability of teaching work. Key words Teaching work, Public universities, Occupational health
Resumo Este artigo tem como principal objetivo analisar a nova organização do trabalho dos professores universitários, estabelecendo uma relação com o panorama de saúde desses trabalhadores. Parte-se do pressuposto segundo o qual a precarização do trabalho nas universidades públicas vem gerando repercussões na saúde dos docentes da educação superior. Realizou-se um estudo qualitativo de caráter exploratório por meio de pesquisa bibliográfica em bases de dados indexadas. Como método de análise, lançou-se mão da analise temática, chegando a quatro categorias empíricas, sendo elas: precarização do trabalho docente; intensificação laboral; aspectos da organização do trabalho docente em universidade; e dados sobre a saúde dos docentes universitários. Verificou-se, na literatura, que prepondera no cenário das universidades o uso de fortes pressões organizacionais e como consequência produz-se a intensificação do trabalho, com destaque para a questão do aumento da exigência de produtividade acadêmica. Constatou-se, ainda, que o tema da sobrecarga de trabalho do professor é recorrente e prevalece a ideia de menor disponibilidade de tempo para o lazer. Além disso, confirmou-se o imperativo da resistência coletiva organizada de maneira a se modificar o quadro de precarização do trabalho do professor.

Palavras-chave Trabalho docente, Universidades públicas, Saúde do trabalhador 


\section{Introdução}

\section{O contexto do capitalismo internacional e as reformas de Estado no Brasil}

Ao final do século XX, instala-se no cenário internacional a crise estrutural do capitalismo neoliberal seguida, no Brasil, de uma ampla e austera reforma de Estado que firma um novo modelo de organização das universidades públicas ${ }^{1}$. Trata-se da reforma da educação superior, atendendo às pressões externas dos organismos internacionais que defendem a inserção da educação pública no campo das atividades econômicas.

O "Consenso de Washington" deve ser lembrado como um marco político importante, sendo que a partir dele a educação superior brasileira vem sofrendo reformas em consonância com determinações externas, em especial do Banco Mundial e do Fundo Monetário Internacional ${ }^{2,3}$. Destaque-se que por parte do Banco Mundial existe a compreensão de que a crise da educação superior deriva de um suposto colapso do modelo de "Estado máximo" e de universidade humboldtiano, no qual defende-se a indissociabilidade entre ensino, pesquisa e extensão, considerado excessivamente unificado e caro. Propõe-se, como saída, a necessidade de se estabelecer a divisão entre universidades de pesquisa e instituições de ensino, um novo postulado ao processo de mercantilização da educação.

Com efeito, Catani et al..$^{4}$ asseguram que em lugar do princípio da indissociabilidade adotaram-se os princípios da diversificação e da diferenciação como novo ideário das políticas de ensino superior, assim como a criação e a disseminação da "instituição não universitária" ou "universidades de ensino" (como o nome o sugere, voltada apenas para o ensino). Trata-se da política de expansão da educação superior no Brasil. Ressalte-se, como lembra Lucas e Leher ${ }^{5}$, que desde 1980 os governantes latino-americanos afinados com o Consenso de Washington vêm apoiando vigorosamente a oferta de vagas no ensino superior do setor privado, subsidiada pelo poder público, com o argumento de que a educação privada é mais barata, cabendo, portanto, a sua ampliação, como imperativo de desenvolvimento econômico.

$\mathrm{Na}$ atual forma de organização do capital, tanto o conhecimento quanto a educação, são considerados bens econômicos necessários à ampliação do poder de competição, entre nações, no mercado globalizado. Portanto, as universidades estão situadas no centro do processo de produ- ção da ciência, tecnologia e inovação, o que têm por consequência a transformação qualitativa do trabalho do professor ${ }^{6}$. Verifica-se, então, a partir da segunda metade dos anos de 1990, o aumento da produção de conhecimento acompanhada de uma maior exigência na produção do trabalho docente, sobretudo no crescimento de publicações científicas que deveriam, sob a expectativa do capital, resultar no incremento de produção tecnológica e na ampliação do número de patentes no país.

A reforma educacional por decorrência do contexto da nova organização do trabalho não é uma particularidade apenas do Brasil. Este fato atinge vários países em uma dimensão mundial. À guisa de ilustração, dois estudos realizados na China $^{7,8}$ abordaram o surgimento de uma ampla reforma do sistema educacional que se originou a partir das mudanças nos padrões das políticas governamentais propostas pelo governo chinês, no início do século vinte e um. Em ambos os estudos, percebeu-se que a sobrecarga de trabalho, o produtivismo acadêmico, a intensificação do trabalho e a oferta de baixos salários têm contribuído para o desenvolvimento de insatisfação, estresse e adoecimento dos professores universitários.

Cabe ainda ressaltar o novo escopo de institucionalização do sistema europeu de educação superior, impulsionado e regulado pela égide da União Europeia, mas com extensão que ultrapassa suas fronteiras políticas. Trata-se, segundo Lima et al. ${ }^{9}$, de um processo sem precedentes na história internacional da educação superior, quando ministros de vinte e nove estados europeus aderiram à chamada Declaração de Bolonha (1999), assumindo como meta o estabelecimento de um único espaço europeu de educação superior, atrativo para estudantes europeus e de alhures. Seu principal objetivo político: "promover o sistema europeu de educação superior em todo o mundo" ${ }^{10}$, tornando-o fortemente competitivo e atrativo a estudantes de outros continentes. Para Lima et al. ${ }^{9}$, o texto da Declaração de Bolonha expõe a opção pelo princípio da competitividade e da racionalidade mercantil, assumindo com clareza o eurocentrismo. Em linhas gerais, o chamado Processo de Bolonha efetivou uma reforma da educação superior europeia na qual sobressai a perda de protagonismo dos estados nacionais. Tal processo ficará para a história como um processo político em que a educação superior enquanto bem público aparece consideravelmente negligenciada. Nele, verifica-se um novo glossário reformador (unidade curricular, resultados da 
aprendizagem, horas de contato etc.) incapaz de promover as mudanças necessárias na organização do trabalho docente.

Trata-se, conforme mostra a literatura crítica, de um novo paradigma sob a influência empresarial a que estão sujeitas as universidades públicas, onde predomina uma lógica contábil. Endossa-se a análise dos autores ${ }^{9}$, quando destacam considerações à luz do processo de Bolonha, sendo a mais significativa, para o Brasil, o fato de que se deve, ao discutir a reforma universitária, debater um projeto de país, fortalecendo a ideia de nação. Assim sendo, defende-se um projeto brasileiro de universidade pública, gratuita, de qualidade e responsabilidade social.

Ressalta-se, por conseguinte, que a atual forma do capitalismo produz uma nova racionalidade organizacional na universidade, a qual se pode denominar de "universidade operacional"11. De acordo com a autora, sobressai na atual estrutura institucional universitária o aumento insano de horas/aula, a diminuição do tempo para mestrados e doutorados e a avaliação pela quantidade de publicações, entre outros fatores.

Para Marra e Melo ${ }^{12}$, cobra-se atualmente, no Brasil, mais eficiência e qualidade das Instituições de Ensino Superior. Em particular, das universidades federais que têm sido interrogadas, por parte da sociedade e do governo, acerca de seus reais objetivos, da rigidez da sua estrutura burocrática, da ineficiência no uso dos recursos e da pouca pertinência social dos serviços prestados. Contudo, embora o ensino superior, em nosso país, seja mais privado do que público, são as universidades públicas que apresentam os melhores índices de qualidade de ensino e de geração de pesquisas $^{13}$. Em contrapartida, são os professores dessas instituições, protagonistas dos processos de produção de conhecimento, que se encontram sobrecarregados em decorrência das novas exigências de organização do trabalho docente ${ }^{14}$. Decerto, verifica-se que o trabalho desses profissionais vem sofrendo alterações profundas, o que mostra a necessidade de novos estudos que permitam dar visibilidade aos problemas relacionados à saúde dos professores da educação pública superior no Brasil.

O fato é que há o reconhecimento internacional, por parte dos governos, de que a educação é constitutiva do desenvolvimento, econômico e social dos países e que especialmente a educação superior representa produção de conhecimento e incremento da ciência e tecnologia. No entanto, a nova configuração do trabalho nas universidades, decorrente das reformas educacionais, tem suscitado repercussões na atividade de trabalho do professor com consequências para o quadro de saúde desses trabalhadores, mas com poucos estudos que analisem as reais dimensões do problema.

Diante desse cenário, tem-se como objetivo: analisar as relações entre a nova organização do trabalho de professores universitários de instituições públicas e a situação de saúde desses profissionais.

\section{Metodologia}

Neste artigo, adotou-se como referencial teórico principal os preceitos do campo da Saúde do Trabalhador que, como campo de conhecimento e de práticas, situa-se no âmago do conflito entre capital e trabalho; sendo que a corrente de pensamento do materialismo histórico exerce posição de destaque como lente de interpretação, filosófica e política, da realidade dos problemas referentes à relação saúde e trabalho ${ }^{15,16}$. Nessa linha de pensamento, um dos pressupostos teóricos fundamentais diz respeito à referência capital do reconhecimento da centralidade do trabalho na determinação social do processo saúde-doença dos grupos humanos ${ }^{16}$. De acordo com Marx $^{17}$, o Homem ao se apropriar da natureza, ele a transforma e transformando-a, transforma a si mesmo de tal modo que esta ação configura o próprio trabalho com suas diferentes formas de organização e divisão como característica de cada formação social. Sustenta-se, portanto, a assertiva segundo a qual o trabalho não é, absolutamente, externo ao homem e nem tampouco neutro no que diz respeito à saúde ${ }^{15}$. Trata-se de uma interação dialética profunda, entre homem, natureza, trabalho e vida.

Realizou-se uma pesquisa bibliográfica de caráter exploratório, tomando como base a metodologia qualitativa de investigação. Segundo Marconi e Lakatos ${ }^{18}$, a pesquisa bibliográfica refere-se a um levantamento da literatura publicada a respeito do tema em estudo por meio de fonte secundária de pesquisa. $\mathrm{O}$ caráter exploratório da pesquisa diz respeito à aproximação com um objeto ainda pouco conhecido ${ }^{19}$. Efetuou-se um inventario na literatura do "estado da questão" restrito à temática "trabalho docente universitário e saúde". Quanto ao enfoque qualitativo de investigação, levou-se a termo a técnica de pesquisa denominada "análise temática"20,21. Além disso, buscou-se responder à seguinte pergunta orientadora de pesquisa: Que temas se destacam 
nas publicações a respeito da saúde e trabalho dos docentes universitários de instituições públicas de ensino superior?

Conforme preconizado por Minayo ${ }^{21}$, a análise temática de textos consiste em três etapas sistematicamente ordenadas: pré-análise, exploração do material e interpretação dos dados obtidos.

\section{Primeira Etapa: Pré-análise}

Refere-se, principalmente, à escolha dos materiais a serem analisados. Para tanto, realizou-se levantamento dos textos em bases de dados de periódicos indexados, cujo processo de seleção bibliográfica efetivou-se nas redes da Biblioteca Virtual de Saúde (BVS), Medline, Lilacs, Scielo e no Portal de Periódicos da Capes. Lançou-se mão das seguintes palavras-chave e descritores de pesquisa: saúde do trabalhador; docentes; trabalho; condições de trabalho; corpo docente universitário; saúde e educador. O procedimento de busca tomou como tópicos de investigação: título, resumo ou assunto. Quanto à estratégia de seleção, acessou-se textos completos, nos idiomas português, inglês e espanhol, sendo encontrados o total de 712 publicações. Na sequencia, procedeu-se a uma leitura exploratória dos resumos, considerando como critério de inclusão os textos que tratavam do tema da saúde e trabalho dos docentes de universidades públicas brasileiras. Como critério de exclusão, subtraímos os artigos relativos aos docentes de nível fundamental e médio que, observe-se, representava um número expressivo no resultado de busca. Além disso, excluímos os estudos realizados em instituições de ensino superior particulares, e ainda dissertações e teses, bem como artigos repetidos. Chegouse a uma definição de 35 artigos que atendiam aos nossos critérios de pesquisa, se constituindo como corpo de análise principal do estudo.

\section{Segunda Etapa: Exploração do material}

Esta fase consiste essencialmente num procedimento classificatório dos textos selecionados. Por conseguinte, efetuou-se sucessivas leituras sobre os textos escolhidos com a preocupação de se capturar suas particularidades para definição dos temas centrais. Tais temas constituíram-se como categorias empíricas de análise, que podem ser compreendidas como unidades de registro primárias para a análise qualitativa do conteúdo dos textos ${ }^{21}$. Saliente-se que a ordenação dos temas seguiu a orientação, do método, que adota como procedimento classificatório aquelas categorias empíricas (temas) que se destacam e significam alguma coisa em relação ao objeto de estudo, especialmente aqueles temas que são recorrentes na literatura.

Tomamos cada texto selecionado como unidade de leitura, chegando a quatro categorias temáticas principais, sendo elas: precarização do trabalho docente; a intensificação laboral e a sobrecarga do tempo de trabalho; aspectos da organização do trabalho docente em universidade; e finalmente, dados sobre a saúde dos docentes universitários. Na próxima seção ("Resultados e Discussão"), apresenta-se a terceira e última etapa da análise temática, qual seja, a interpretação dos dados obtidos.

\section{Resultados e Discussão}

\section{Precarização do Trabalho Docente}

Na perspectiva das publicações a respeito do trabalho dos professores universitários se destaca a ideia de acordo com a qual o processo de precarização do trabalho advém do processo de reestruturação produtiva, combinando evolução tecnológica com flexibilização do trabalho ${ }^{22,23}$. De acordo com os autores, prepondera no cenário das universidades o uso de fortes pressões organizacionais e como consequência, produz-se a intensificação do trabalho, com destaque para o tema do aumento da exigência de produtividade acadêmica.

No estudo de Mancebo ${ }^{24}$ sobressai a noção de aumento da precarização do trabalho na universidade em correspondência com a ampliação de contratos temporários e do número significativo de professores substitutos. O estudo de Coutinho et al. ${ }^{23}$ menciona o fato de que professores em situação de vínculo laboral incerto são levados a exercerem outras atividades profissionais além da docência, com o intuito de aumentar os rendimentos para sustento material da vida. No entanto, lembremos que mesmo os professores com vínculo de trabalho estável padecem da precarização das condições salariais, visto que sofrem arrocho de remuneração e as supostas correções de pagamento são, em verdade, concessões de gratificação, não incorporadas ao seu salário base ${ }^{14}$.

Verificou-se também, nos artigos analisados, uma correlação entre a incerteza dos contratos temporários e o enfraquecimento do coletivo de professores. Esta tese, partilhada por Maués ${ }^{14} \mathrm{e}$ Lacaz $^{25}$, evidencia o fato de que se torna fundamental o fortalecimento da organização dos tra- 
balhadores docentes para que se modifiquem as condições de trabalho e a situação de saúde dos docentes universitários. Segundo esses autores, a resistência organizada sob a liderança do sindicato nacional dos profissionais de educação (ANDES-SN) é condição para que se mitigue a precarização, a intensificação e a flexibilização do ensino público superior.

Segundo Lemos ${ }^{26}$, o panorama de precarização nas universidades federais abre caminho para que os professores vivenciem uma condição de trabalho deteriorada, com um impacto significativo para a vida desses trabalhadores. Ganha destaque a ideia segundo a qual a precarização do trabalho do modo como ocorre hoje, sob a égide do capitalismo global, seria sobretudo a precarização da existência da pessoa, ou seja, a precarização no trabalho atinge a qualidade constitutiva da forma de se viver ${ }^{27,28}$.

\section{A intensificação laboral e a sobrecarga do tempo de trabalho}

A intensificação do trabalho docente diz respeito, sobretudo, ao alargamento da carga de trabalho do professor ${ }^{23}$. Contudo, essa ampliação do tempo de trabalho acontece de modos diferentes, a depender da inserção dos professores. Estudos como os de Coutinho et al. ${ }^{23}$ observaram que os docentes vinculados à graduação queixam-se mais do elevado número de aulas e superlotação das salas enquanto que os professores ligados à pós-graduação enfatizam a exigência do aumento da produção científica, mormente da cobrança de publicação de artigos.

De acordo com Bosi $^{29}$ e Mancebo ${ }^{24}$, percebese no cotidiano universitário uma aceleração da produção docente, bem como o prolongamento do tempo que o professor despende com o trabalho. Para essas autoras, a exigência despropositada do aumento da produção acadêmica pode ameaçar a qualidade da educação e da pesquisa. Desse modo, desenha-se, nas universidades, uma "sociedade da urgência" ${ }^{24}$ que leva ao estabelecimento de horários atípicos e a precipitação no desempenho das atividades, abreviando o tempo de convivência, bem como o campo coletivo de criação.

O trabalho docente é considerado um trabalho imaterial, sendo preponderante a atividade intelectual ${ }^{6}$. Trata-se de um trabalho que cria produtos imateriais, como o conhecimento, a informação e as relações afetivas ${ }^{30}$. Mas é igualmente perceptível o engajamento do corpo, conforme evidencia o estudo de Fontana e Pinheiro ${ }^{31}$; onde verificou-se que as queixas mais prevalentes foram dores no corpo, principalmente lombalgia, que estão associadas a longos períodos de atividades de trabalho em pé e ao intenso clima de tensão vivenciado no ambiente laboral.

Não obstante, estudos como os de Gradella Junior $^{32}$ e Alvarez ${ }^{33}$ constataram que não há tempo para pausa ou descanso, o que pode estar relacionado a sinais de saúde de cunho emocional e psíquico como estresse, gastrite, labirintite, enxaquecas, entre outros. Não se pode falar em jornadas formais de trabalho (quarenta horas semanais), já que o docente "trabalha à noite, nos feriados e finais de semana" ${ }^{33}$. Consoante Coutinho et al. ${ }^{23}$ e Lopes $^{34}$, a invasão do espaço e do tempo pela tribulação do trabalho do professor que deveriam ser destinados ao lazer e repouso são apontadas como fator de sofrimento e desgaste.

Ainda no que tange à organização do tempo de trabalho do professor é merecedor de destaque o tema das tecnologias informacionais. Pois, em que pese o seu fundamental suporte laboral, sabe-se que esses artifícios tecnológicos ampliam a possibilidade do dispêndio do tempo de descanso, comprometendo o tempo de recuperação, o que pode contribuir para o desencadeamento de exaustão física e mental ${ }^{23}$.

No estudo de $\mathrm{Lemos}^{26}$, destaca-se que a sobrecarga de trabalho tem consequências indesejáveis, como ausência do lazer e perda de controle sobre o projeto acadêmico. A autora verificou que a principal contradição vivida pelo docente é a perda da autonomia profissional, uma vez que está submetido a diversos controles internos e externos do sistema denominado meritocrático em vigor nas universidades, cujas exigências ultrapassam a capacidade física e psíquica do professor para responder adequadamente.

Nessa mesma perspectiva, o estudo de Léda e Mancebo 35 , a respeito do "Programa de Apoio a Planos de Reestruturação e Expansão das Universidades Federais" (REUNI), volta-se para o tópico referente ao crescimento numérico das universidades no Brasil e a perda de autonomia das mesmas, já que se encontram submetidas a um controle tecnocrático de cumprimento excessivo de metas quantitativas (sem o suficiente aporte de recursos). Para as autoras, a heteronomia e a precarização da universidade são expressões atuais da universidade e do trabalho docente no Brasil.

Constatou-se, ainda, que o tema da sobrecarga de trabalho do professor é recorrente e prepondera a ideia da menor disponibilidade 
de tempo para o lazer e atividades prazerosas. Fontana e Pinheiro ${ }^{31}$ salientam que as atividades de professor exigem um processo de atualização constante para o cumprimento de suas funções acadêmicas, fazendo com que existam, com frequência, jornadas extras de trabalho. Este tema foi também objeto de estudo de Oliveira Filho et al. ${ }^{36}$, no qual sobressai o tema das relações de gênero e trabalho. Consoante os autores, as professoras (do sexo feminino) vivenciam uma situação de sobrecarga ocupacional com implicações de amplas proporções para a saúde. Os resultados deste estudo demonstram que as professoras estão submetidas à extensa jornada de trabalho, como constantes tarefas extraclasses, cumprimento de tarefa com prazo curto de tempo, múltiplos empregos e extensa carga horária de sala de aula.

Quanto ao tema da sala de aula, é digno de nota o estudo de Arbex et al. ${ }^{37}$, no qual os autores verificaram, por meio de entrevistas realizadas com professores universitários readaptados - quer dizer, docentes afastados das funções de sala de aula por motivo de saúde -, que deixar a sala de aula foi considerado positivo para a saúde, visto que a relação com os alunos, aquilo que um dia foi motivo de prazer, pode tornar-se fonte de sofrimento e insatisfação no trabalho depois de um certo tempo. Os autores constataram ausência de percepção crítica, por parte dos professores entrevistados, a respeito do processo de trabalho como fator de adoecimento.

\section{A organização do trabalho docente em universidade}

No estudo de Maues ${ }^{14}$, descreve-se o conjunto das atividades que demarcam a vida acadêmica do professor:

A quantidade de 'produtos', textos, livros, orientações, participação em eventos com apresentação de trabalho, organização de eventos, emissão de pareceres para as agências de fomento e revistas, participação em bancas de defesa e de concurso, as disciplinas ministradas na graduação e na pós-graduaçãa $o^{14}$.

De acordo com a autora, a identidade social das universidades públicas vem sofrendo alterações e a sua nova configuração está próxima a de empresas privadas, cujos indicadores estão pautados em dados quantificáveis e o mérito do trabalho vinculado a resultados mensuráveis.

Cabe-nos, nesse ponto, uma reflexão mais precisa a respeito do tema do produtivismo acadêmico. Verificou-se, por meio de estudos empí- ricos e ensaios críticos, que os docentes vinculados aos programas de pós-graduação estão submetidos a um ritmo intenso de produção acadêmica, principalmente publicação de artigos científicos, sob o risco de serem excluídos do quadro de docentes permanentes das suas instituições. A avaliação, promovida pela CAPES - órgão governamental regulador da pós-graduação no Brasil -, tem suscitado sofrimento e constrangimento com efeitos desconhecidos sob a saúde psíquica e somática desses trabalhadores. Constata-se, na rotina dos docentes, uma ameaça permanente de desligamento dos programas, o que pode causar perda de reconhecimento acadêmico e prejuízo no capital simbólico de pertencimento à pósgraduação ${ }^{14}$. Ademais, consoante a observação de Silva Junior ${ }^{6}$, o modelo de avaliação da CAPES provoca um clima de competição entre os pesquisadores de uma mesma área e de disputa por recursos financeiros, além de exercer pressão sobre o corpo discente.

Constatação semelhante é mencionada por Marra e Mello ${ }^{12}$, ao descrever na atual configuração do trabalho em universidades características como concorrência entre os departamentos por recursos e poder de influência, presença de verdadeiros feudos por área de conhecimento, burocracia profissional associada ao personalismo e o predomínio da individualidade sobre a coletividade.

Sabe-se que os fatores inerentes ao próprio processo e à organização do trabalho docente podem funcionar como estressores, precipitar doenças ou gerar insatisfações ${ }^{38}$. Além das exigências atualmente em vigor no trabalho docente, aqui citadas, Fontana e Pinheiro ${ }^{31}$ mencionam ainda desavenças entre grupos de trabalho e desrespeito por parte dos alunos. Quanto a este último aspecto citado, Gradella Junior ${ }^{32}$ defende o ponto de vista segundo o qual a socialização do conhecimento com os alunos e o processo de troca na relação pedagógica é reconhecidamente prazerosa, mas pode também mostrar-se como fonte de sofrimento, devido à possibilidade de se vivenciar conflitos.

No que concerne à temática da organização do trabalho docente em universidade, chama a atenção, embora ainda pouco estudado, o problema do Assédio Moral (AM). Consoante Caran et al. ${ }^{39}$, o espaço acadêmico é propício à ocorrência de situações de assédio moral devido a ser um ambiente favorável à competitividade. Quanto à descrição do tipo de assédio sobressaiu, no referido estudo, o assédio moral horizontal (aquele que acontece entre colegas), seguido do assédio 
moral descendente (aquele que sucede-se do superior em relação ao subordinado).

Considera-se, ainda pertinente ao tema da organização do trabalho docente, as atividades oficiais que não são vistas como parte do trabalho acadêmico, mas que são exigências institucionais do trabalho dos professores de ensino superior, tais como: preenchimento de relatórios e elaboração de planos de atividades, participação em grupos ou comissões de trabalho nos departamentos e encargos administrativos e responsabilidade de gestão ${ }^{32,33}$. De acordo com Oliveira Filho et al. ${ }^{36}$, a categoria docente é uma das mais expostas a ambientes conflituosos e de alta exigência de trabalho e tarefas extraclasses, como reuniões e atividades adicionais.

Na literatura, encontram-se importantes aspectos, não explícitos, do trabalho docente que devem obter visibilidade de modo a se mudar a organização laboral em universidades. Em estudo realizado por $\operatorname{Costa}^{40}$ a respeito de docentes de universidades na área médica, a autora destaca alguns fatores que limitam mudanças na prática deles. Entre os quais, ressaltam-se a resistência a mudanças, o individualismo dos professores e a falta de identidade profissional como docente.

De fato, verificou-se nas publicações, a concepção frequente da pouca valorização dada à formação pedagógica do professor universitário, o que pode ser atribuído ao desmerecimento das atividades de ensino nas universidades, nas quais os estímulos para a atuação e os critérios de progressão na carreira têm-se fundamentado mais na produção científica do que no exercício da docência ${ }^{40}$. Contribui para esse fato o próprio desenvolvimento do conhecimento científico específico de cada área, que tem se tornado cada vez mais fragmentado e especializado.

De acordo com Chauí ${ }^{11}$, na nova estrutura de organização do trabalho em universidades desapareceu a marca essencial da docência, qual seja: a formação. Por sua vez, a pesquisa seguindo esse padrão organizacional, caracteriza-se por modalidades de consecução nas quais se deve recortar a realidade de maneira a focalizar apenas o aspecto sobre o qual está destinada a intervenção imediata, sem tempo para reflexão ou críticas que levem a mudanças na realidade.

Não obstante, é merecedor de registro o estudo de Fontana e Pinheiro ${ }^{31}$ realizado no departamento de ciências da saúde de uma universidade do estado do Rio Grande do Sul, no qual grande parte dos entrevistados citou como elementos de satisfação no trabalho a "apropriada estrutura física e infraestrutura, bons laboratórios para a prática do ensino, organização da universidade, boas relações interpessoais e o salário acima da média da profissão" ${ }^{31}$. Embora estas variáveis não tenham sido quantificadas no estudo, esse resultado se distingue da maioria das pesquisas que criticam o trabalho e o modo da sua organização nas universidades públicas.

Torna-se igualmente distinto, no tópico referente à relação entre satisfação e sofrimento no trabalho do professor universitário, o tema da aposentadoria observado por Silva Junior ${ }^{6}$. Curiosamente, o autor analisou em seu estudo, a situação dos docentes que recebem a comunicação compulsória da aposentadoria, o que costuma levá-los ao adoecimento. De acordo com o autor, há, em muitas instituições universitárias, aqueles docentes que se aposentam, mas que permanecem trabalhando com outros tipos de vínculos. Os estudos de Marra e Melo ${ }^{12}$ evidenciaram o fato de se viver nas universidades um período de ambiguidade cultural e dilema entre a tradição e a renovação na organização do trabalho, o que deveria ser objeto de novos estudos.

\section{Dados sobre a saúde dos docentes universitários}

Quanto ao tema da saúde dos docentes, em relação ao trabalho em universidades, ganham destaque referências à saúde mental e esfera psicoafetiva $^{25}$. De acordo com Gradella Junior ${ }^{32}$, a saúde mental dos docentes é condição para que ele exerça a sua função, já que as relações de afetividade e emocionais são características essenciais do trabalho docente.

Em estudo realizado por Lima e Lima-Filho ${ }^{38}$, junto a professores da Universidade Federal de Mato Grosso do Sul, os autores chamam atenção para a elevada manifestação de queixas relacionadas à saúde mental. Os sintomas de maior prevalência foram: cansaço mental, estresse, ansiedade, esquecimento, frustração, nervosismo, angústia, insônia e depressão. Os resultados mostram que os docentes apresentam exaustão emocional. Na avaliação dos autores, os dados obtidos são indicativos sobre como os processos de trabalho, atualmente em curso em instituições universitárias públicas brasileiras, interferem na saúde de professores.

Caran et al. ${ }^{41}$ realizaram um estudo transversal, compreendendo 54 professores pertencentes a uma instituição pública, de ensino superior, localizada no interior do estado de São Paulo. Foram incluídas questões acerca de dados sociodemográficos, das condições de trabalho e 
da percepção de riscos ocupacionais psicossociais (ROP) e possíveis repercussões na saúde. Segundo os autores, esse grupo de risco é percebido em situações onde exista importante nível de exigência para o desempenho de suas funções, insatisfações quanto à remuneração, jornada e ritmo de trabalho e problemas com relacionamentos pessoais no trabalho. Como consequência, estes fatores são passíveis de desencadear reflexos negativos na saúde; com frequência, ocorrem repercussões psíquicas causando neuroses, síndrome depressiva ou manifestações isoladas de ansiedade, distúrbios do sono, mudanças do humor e do comportamento, até a síndrome de Burnout, entre outros.

Cabem-nos, neste ponto, algumas observações relativas à Síndrome de Burnout. De acordo como Trigo et al..$^{42}$, o termo burnout é definido, segundo um jargão inglês, como aquilo que deixou de funcionar por absoluta falta de energia. Metaforicamente é aquilo, ou aquele, que chegou ao seu limite, com grande prejuízo em seu desempenho físico ou mental. De acordo com a OMS

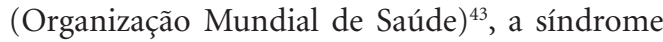
de burnout é um processo iniciado com excessivos e prolongados níveis de estresse (tensão) no trabalho As características individuais das pessoas associadas às do ambiente $\mathrm{e}$ às do trabalho propiciam o aparecimento dos fatores multidimensionais da síndrome, sendo elas: exaustão emocional, distanciamento afetivo (despersonalização) e baixa realização profissional.

A ocorrência de burnout em professores é considerada, atualmente, um problema social de extrema relevância. Segundo Sousa e Mendonça ${ }^{44}$, ela é consequência de reações a fontes de estresse ocupacional que se acumulam. Para Carlotto e Câmara ${ }^{45}$, a impossibilidade de mudança estrutural nas instituições de ensino, para os professores, pode levar à utilização da estratégia de afastamento, de fuga e de esquiva no trabalho, porém isso resulta em maior exaustão emocional. A despersonalização eleva-se na medida em que há uma maior utilização da estratégia de afastamento. Conclui-se que, para esses autores, existe uma relação entre organização universitária e trabalho docente que terá como resultado provável consequências de amplas proporções sobre a saúde dos trabalhadores da educação, necessitando de aprofundamento com novas investigações.

Merecem atenção, ainda, os estudos sobre a voz dos professores universitários, porquanto esses trabalhadores apresentam alto risco para desenvolver o distúrbio vocal de ordem ocupacional. Em pesquisa realizada na Faculdade de
Medicina de Ribeirão Preto da Universidade de São Paulo/USP ${ }^{46}$, foi evidenciada uma prevalência elevada de sintomas vocais. Para os autores, há necessidade de ações preventivas e de orientação vocal para esses professores. Já para Servilha e Delatti ${ }^{47}$, em estudo realizado junto a professores universitários da área da saúde, a alteração vocal tem origem multifatorial e o ruído não pode ser considerado o único fator de risco para a saúde deles, sendo necessário combinar avaliações objetivas e subjetivas sobre os problemas de saúde deste segmento de trabalhadores.

Considere-se ainda o fato de que nas publicações a respeito do tema da saúde dos docentes universitários, existe um escasso debate sobre o uso de estimulantes, por parte de professores, para se incitar a vigília ${ }^{6}$. O que sinaliza para a realização de novos estudos cujo foco de investigação deva incidir sobre o consumo de drogas lícitas e ilícitas por parte desta categoria profissional. Não obstante, o estudo de Oliveira Filho et al. ${ }^{36}$ evidenciou o consumo habitual de álcool entre professores universitários com episódios de consumo excessivo, sendo considerado pelos autores um quadro preocupante. Estudos como os de Coutinho et al. ${ }^{23}$ e Gradella Jr. ${ }^{32}$ mostram que as transformações em curso no trabalho dos professores universitários geram alterações relativas a maneira de ser, viver e sentir o próprio trabalho.

\section{Considerações Finais}

Ante o panorama das relações de trabalho e saúde dos docentes universitários presente na literatura, compreende-se como necessário pensar em espaços de apoio aos docentes, onde esses profissionais possam dialogar a respeito de ansiedades e dúvidas sobre a saúde ${ }^{48}$. Importante é que estes espaços assumam um caráter pedagógico, de troca entre os participantes, um espaço de fala e de escuta, onde se coloque o próprio trabalho como centro do debate e objeto de discussão para a promoção de mudanças no trabalho. Porquanto, confirmou-se que existem apreciações, nas publicações analisadas, que vislumbram a necessidade de intervenções institucionais nas universidades de caráter coletivo para a promoção de ambientes laborais mais saudáveis ${ }^{37}$.

Participamos do pensamento de Sennett ${ }^{49}$ quando afirma que a competição e o individualismo provocados pelas novas formas de organização do trabalho desalentaram os trabalhadores e fez desaparecer "o ethos do bom trabalho pelo bom trabalho" ${ }^{49}$. Ao contrário, verifica-se no co- 
tidiano universitário o afastamento de valores que têm por base a ideia de universidade como promotora da formação humana, como tornar efetivos vínculos de proximidade e apreço, sendo imperativo o resgate do real ethos do trabalho: criativo, coletivo e emancipador, como preconizado, por Gramsci, na "Concepção Dialética da História" ${ }^{50}$. Consoante Tavares ${ }^{3}$, constatou-se como indispensável a crítica ao ideário liberal que tem a divisão do trabalho como base da concepção de desenvolvimento. Assim, "parte-se o homem e apartam-se os homens"3.

Todavia, é no próprio contexto social de clave neoliberal que a organização de trabalho fica

\section{Colaboradores}

KR Souza, ALO Mendonça, MAS Rodrigues, EG Felix, LR Teixeira, MBM Santos e M Moura participaram igualmente de todas as etapas de elaboração do artigo: (levantamento dos materiais de revisão da literatura; concepção e análise dos dados e redação do manuscrito). Quanto à aprovação da versão final ficou sob a responsabilidade de ALO Mendonça e KR Souza. submetida a certa vulnerabilidade, já que para efetivar-se, com eficácia, depende da adesão dos trabalhadores ${ }^{51}$. Diante dessa afirmação, avalia-se como essencial o fortalecimento da organização dos trabalhadores docentes, especialmente do seu sindicato.

Finalmente, constatou-se que os rebatimentos na saúde dos docentes, sob a nova organização do trabalho, são alarmantes e necessitam de novas pesquisas que utilizem diferentes metodologias com a participação dos trabalhadores como protagonistas e autores do processo de mudanças na realidade da educação superior no Brasil.

\section{Referências}

1. Chaves VLJ. Parceria público-privada na gestão da universidade pública brasileira. Cadernos de Educação (UFPel) 2009; 33:311-324.

2. Leher R. Crise estrutural e função social da universidade pública. Temporalis 2010; 1:15-39.

3. Tavares MA. Trabalho docente na universidade pública: uma reflexão sobre o produtivismo acadêmico na contemporaneidade. Argumentum 2011; 3(1):238-250.

4. Catani AM, Oliveira JF, Michelotto RM. As políticas de expansão da educação superior no Brasil e a produção do conhecimento. Fundamentos en humanidades 2007; 1(23):47-64.

5. Lucas LCG, Leher R. Aonde vai a educação Pública brasileira? Educ Soc 2001; 22(77):255-266.

6. Silva Junior JR. O professor pesquisador nas universidades públicas no contexto da internacionalização do capital: a produtividade do trabalho imaterial superqualificado. Rev. Port. de Educação 2009; 22(1):145-177.

7. Ge C, Yang X, Fan Y, Kamara AH, Zhang X, Fu J, Wang L. Quality of life among Chinese college teachers: A cross-sectional survey. Public Health 2011; 125(5):308310.

8. YongW. Research on the source of occupational stress of college teachers. Human Health and Biomedical Engineering (HHBE).International Conference; 2011 Set 19-22; Jilin, China; 2011.

9. Lima L, Azevedo MLN, Catani AM. O Processo de Bolonha, a avaliação da educação superior e algumas considerações sobre a Universidade Nova. Avaliação 2008; 13(1):7-36.

10. Azevedo MLN. A integração dos sistemas de educação superior na Europa. De Roma a Bolonha ou da integração económica à integração académica. In: Silva Junior JRS, Oliveira JF, Mancebo D, organizadores. Reforma universitária: dimensões e perspectivas. Campinas: Alínea; 2006. p.171-1711.

11. Chaui M. A universidade pública sob nova perspectiva. Revista Brasileira de Educação 2003; 24:5-15. 
12. Marra AV, Melo MCOL. A prática social de gerentes universitários em uma instituição pública. Rev. adm. Contemp 2005; 9(3):9-31.

13. Vieira EMF, Bellen HMV, Fialho FAP. Universidade em tempo de mudança. Cad. EBAPE. 2006; 4(3):1-7.

14. Maues O. A reconfiguração do trabalho docente na educação superior. Educ 2010; (N. Esp. 1):141-160.

15. Laurell AC, Noriega M. Processo de produção e saúde: trabalho e desgaste operário. São Paulo: Ed. Hucitec; 1989.

16. Lacaz FAC. O campo Saúde do Trabalhador: resgatando conhecimentos e práticas sobre as relações trabalhosaúde. Cad Saude Publica 2007; 23(4):757-766.

17. Marx K. Manuscritos econômico-filosóficos. São Paulo: Abril Cultural; 1974.

18. Marconi MA, Lakatos EM. Fundamentos de metodologia científica. São Paulo: Atlas; 2003.

19. Gil AC. Métodos e técnicas de pesquisa social. São Paulo: Atlas; 1999.

20. Severino AJ. Metodologia do trabalho científico. São Paulo:Cortez;1996.

21. Minayo MCS. O desafio do conhecimento: pesquisa qualitativa em saúde. São Paulo, Rio de Janeiro: Hucitec, Abrasco; 2010.

22. Pinzón JG, Ribas JMB, Uribe-rodriguez AF, Acevedo JF, Sanchez MCP. El capitalismo organizacional como fator de riesgo psicossocial: efectos psicológicos colaterales de las nuevas condiciones de trabajo em hospitales y universidades de natureza pública. Rev. Psicologia desde el Caribe 2011; 28:166-196.

23. Coutinho MC, Magro MLPD, Budde C. Entre o prazer e o sofrimento: um estudo sobre os sentidos do trabalho para professores universitários. Psicologia: Teoria e Prática 2011; 13(2):154-167.

24. Mancebo D. Trabalho docente: subjetividade, sobre implicação e prazer. Psicol. Reflex. Crit 2007; 20(1):74-80.

25. Lacaz FAC. Capitalismo organizacional e trabalho: a saúde do docente. Univ. Soc. 2010; 45:51-59.

26. Lemos D. Trabalho docente nas universidades federais: tensões e contradições. Cad. CRH 2011; 24(N. Esp.):105-120

27. Alves G. Crise estrutural do capital, Maquinofatura e a precarização do trabalho: A Questão Social no Século XXI. Textos \& Contextos 2013; 12(2):221-234.

28. Antunes R. Desenhando a nova morfologia do trabalho no Brasil. Estud. av. 2014; 28(81):39-53.

29. Bosi AP. A precarização do trabalho docente nas instituições de ensino superior no Brasil nesses últimos 25 anos. Educ. Soc 2007; 28(101):1503-1523.

30. Hardt M, Negri A. Multidão: guerra e democracia na era do império. Rio de Janeiro: Record; 2005.

31. Fontana, RT, Pinheiro DA. Condições de saúde auto -referidas de professores de uma universidade regional. Rev. Gaúcha Enferm 2010; 31(2):270-276.

32. Gradella Júnior O. Sofrimento psíquico e trabalho intelectual. Cadernos de Psicologia Social do Trabalho 2010; 13(1):133-148

33. Alvarez D. Cimento não é concreto, tamborim não é pandeiro, pensamento não é dinheiro! Para onde vai a produção acadêmica? Rio de Janeiro: Myrrha; 2004

34. Lopes MCR. "Universidade Produtiva" e trabalho docente flexibilizado. Estudos e Pesquisa em Psicologia 2006; 6(1):35-48.

35. Léda DB, Mancebo D. REUNI: heteronomia, precarização da universidade e do trabalho docente. Educação e Realidade 2009; 34(1):49-64.
36. Oliveira Filho A, Netto-Oliveira ER, Oliveira AAB, Qualidade de vida e fatores de risco de professores universitários. Rev. educ. fis. UEM 2012; 23(1):57-67.

37. Arbex APS, Souza KR, Mendonça ALO. Trabalho docente, readaptação e saúde: a experiência dos professores de uma universidade pública. Physis 2013; 23(1):263-284.

38. Lima MFEM, Lima-Filho DO. Condições de trabalho e saúde do/a professor/a universitário/a. Ciências e Cognição 2009; 14(3):62-82.

39. Caran VCS, Secco IAO, Barbosa DA, Robazzi MLCC. Assédio moral entre docentes de instituição pública de ensino superior do Brasil. Acta Paul Enferm 2010; 23(6):737-744.

40. Costa NMSC. Docência no ensino médico: por que é tão difícil mudar? Rev. bras. educ. med. 2007; 31(1):2130 .

41. Caran VCS, Freitas FCT, Alves LA, Pedrão LJ, Robazzi MLCC. Riscos ocupacionais psicossociais e sua repercussão na saúde de docentes universitários. Rev. Enferm UERJ 2011; 19(2):255-261.

42. Trigo TR, Teng CT, Hallak JEC. Síndrome de burnout ou estafa profissional e os transtornos psiquiátricos. Rev. psiquiatr. Clín. 2007; 34(5):223-233.

43. World Health Organization (WHO). Guidelines for the primary prevention of mental, neurological and psychosocial disorders: Staff Burnout. Vol.5. In: World Health Organization (WHO). World Health Organization Geneva Division of Mental Health World Health Organization. Geneva: WHO; 1998. p. 91-110.

44. Sousa IF, Mendonça H. Burnout em professores universitários: impacto de percepções de justiça e comprometimento afetivo. Psic.: Teor. e Pesq 2009; 25(4):499-508.

45. Carlotto MS, Camara SG. Síndrome de Burnout e estratégias de enfrentamento em professores de escolas públicas e privadas. Psicol. educ 2008; (26):29-46.

46. Fabricio MZ, Kasama ST, Martinez EZ. Qualidade de vida relacionada à voz de professores universitários. Rev. CEFAC 2010; 12(2):280-287.

47. Servilha EAM, Delatti MA. Percepção de ruído no ambiente de trabalho e sintomas auditivos e extra-auditivos autorreferidos por professores universitários. J. Soc. Bras. Fonoaudiol 2012; 24(3):233-238.

48. Koetz L, Rempel C, Perico E. Qualidade de vida de professores de Instituições de Ensino Superior Comunitárias do Rio Grande do Sul. Cien Saude Colet 2013; 18(4):1019-1028.

49. Sennett R. O artificie. Rio de Janeiro: Record; 2012.

50. Gramsci A. Concepção dialética da história. Rio de Janeiro: Civilização Brasileira; 1986.

51. Oliveira MB. A avaliação neoliberal na universidade e a responsabilidade social dos pesquisadores. Sci. Stud 2008; 6(3):379-387.

Artigo apresentado em 03/04/2015

Aprovado em 02/04/2016

Versão final apresentada em 04/04/2016 